\title{
Evaluating patient experiences in decentralised acute care using the Picker Patient Experience Questionnaire; methodological and clinical findings
}

Ann-Chatrin Linqvist Leonardsen ${ }^{1 *}$, Vigdis Abrahamsen Grøndahl², Waleed Ghanima', Espen Storeheier ${ }^{3}$, Anders Schönbeck ${ }^{4}$, Thor-Asbjørn Løken ${ }^{5}$, Nina Carine Mikkelsen Bakken ${ }^{6}$, Guro Steine Letting ${ }^{7}$, Réné Holst ${ }^{8}$ and Lars-Petter Jelsness-Jørgensen ${ }^{2}$

\begin{abstract}
Background: Decentralised acute care services have, through the establishment of municipality acute wards (MAWs), been launched in Norway. The aim is to provide treatment for patients who otherwise would need hospitalisation. Currently there is a lack of studies investigating patient experiences in such services. The aims of this study were therefore to a) translate and validate the Picker Patient Experience Questionnaire (PPE-15) in Norwegian, and b) assess patient experiences in decentralised acute care, and potential factors associated with these experiences.

Methods: Patients were recruited from five municipal acute wards in southeastern Norway during the period from June 2014 to June 2015. Data on socio-demographics, length of stay and comorbidity (Charlson comorbidity index (CCI)) were collected. Patients completed the Picker Patient Experience Questionnaire (PPE-15) and the EuroQOL 5-dimension, 3-level version. Convergent validity of the PPE-15 was assessed by correlation of items in PPE-15 and the Nordic Patient Experience Questionnaire (NORPEQ). A retest of the PPE-15 was performed in a subgroup of patients approximately 3 weeks after baseline assessment. Test-retest agreement was assessed with Cohens' unweighted Kappa. Results: A total of 479 patients responded, median age 78.0 years and $41.8 \%$ men. A total of 68 patients participated in the retest. Testing of convergent validity revealed an overall weak to moderate correlation. Kappa statistics showed from fair to good test-retest agreement. Most problems were related to continuity and transition, while fewest problems were related to respect for patient preferences. A higher Charlson comorbidity score was the only variable that was negatively associated with patient experience.
\end{abstract}

Conclusion: Patients reported problems in several items of the PPE-15 after discharge from decentralised acute wards. The findings from the current study may be helpful for planning ways to improve quality of care, e.g., by providing feedback to healthcare personnel or by using patient experience as a quality indicator.

Keywords: Decentralised, Acute healthcare, Patient experiences, Questionnaire, Self-reported health, Comorbidity, Quality, Primary care, Socio-demographics

\footnotetext{
*Correspondence: dleo@online.no

'Østfold Hospital Trust, University of Oslo, P.O. Box 300, NO-1714 Grålum,

Norway

Full list of author information is available at the end of the article
} 


\section{Background}

The patient experience refers to how the patients, their families and other persons who participate in their care feel about the process and structure of care, as well as the outcomes of care [1]. There is a growing recognition that patients' perspectives are essential in achieving high quality care $[2,3]$. Integrating patients' perspectives into the evaluation of healthcare delivery is important because they indicate ways to improve care, enhance strategic decision making, meet patients' expectations, effectively manage and monitor healthcare performance, and document benchmarks for healthcare organisations $[4,5]$.

Due to the lack of a common definition, the measurement of patient experiences remains challenging [6]. Despite its different meanings, patient experience is often used interchangeably with terms such as patient satisfaction, perceptions or preferences $[7,8]$. However, patient experiences are usually considered less subjective than patient satisfaction because patients may be satisfied with healthcare even though they have negative experiences and vice versa $[9,10]$. Nevertheless, several factors have been found to influence these experiences, including age, gender, housing and employment status, ethnicity, self-rated health, multimorbidity, and care ward characteristics [11-13].

In the Nordic countries, regular assessment of patient experiences has been practiced for a long time [14]. For instance, as a part of the national quality indicators in specialist healthcare services, Norway implemented annual patient experience surveys in all hospitals in 2011 [15]. Although they are more commonly used in hospitals, municipalities are also obliged, according to the Norwegian National Health and Care Service Act, to collect patient experiences and to take these into account when planning and organising primary healthcare services [16].

To respond to future healthcare challenges, a national healthcare reform (the Coordination Reform (CR)) has been gradually implemented in Norway from 2012 to 2016 $[16,17]$. One of the main objectives of the reform was to increase the total proportion of patients who accessed health services within their local community. As a direct consequence of the $\mathrm{CR}$, all Norwegian municipalities were legislated to offer a 24-h acute healthcare service beginning in 2016 (Municipal Acute Wards, MAWs). Eligible patients are those who would be normally admitted to a hospital for a condition that can be managed in a general practice setting and within a timeframe of $72 \mathrm{~h}$ [18]. Throughout Norway, MAWs are organised differently, some being located in nursing homes, some in "houses of health, in local medical centres in relation to a casualty or a hospital. Some MAWs have employed their own doctors dedicated to the service on a 24-h basis, while other places have employed doctors only during daytime. All of the MAWs have daily doctors' visits on weekdays. Moreover, the MAWs differ in terms of number of beds and services offered [19].

Information about patient experiences in primary healthcare, particularly in decentralised acute healthcare, are either limited or lacking [20-23]. Only two qualitative papers describing patients' perspectives on MAWs have been published to date, finding for example that patients view MAWs as "almost a hospital", but at the same time different with regard to person centeredness and diagnostic opportunities [24, 25]. Furthermore, the relative influence of socio-demographic variables, length of stay, self-rated health and comorbidity on these experiences remains unknown. Such knowledge could be useful when planning and improving alternatives to hospital treatment, such as MAWs.

The aims of this study were: a) to translate and validate the Picker Patient Experience Questionnaire (PPE-15) in Norwegian, and b) to assess patient experiences in decentralised acute care, and potential factors associated with these experiences.

\section{Methods}

\section{Setting and participants}

Østfold County, located in southeastern Norway, consists of approximately 300,000 inhabitants. The county is divided into 17 municipalities that belong to the same hospital catchment area. In addition to the hospital, a total of five MAWs have been established in different geographical locations throughout the county. The MAWs consist of four to eleven beds, dependent on the population size of their catchment area. Some laboratory services are offered in all of these facilities, while $\mathrm{x}$-ray is accessible in three only.

Participants were recruited from all of the five MAWs during the period from June 2014 - June 2015 using a purposive, total population sampling method; all patients $\geq 18$ years who had stayed in the MAW for a minimum $24 \mathrm{~h}$ and who were discharged alive were invited to participate.

\section{Data collection}

Socio-demographic variables were self-reported by the patients and included the following: gender, age, civil status (married, single, widow/widower, in a relationship), housing status (living alone or not), educational level (compulsory school, upper secondary school or university), and employment status (still working or not). Information concerning the length of stay was collected from medical records.

Comorbidity was collected using the Charlson comorbidity index (CCI) [26]. The risk of death associated with each of 19 predefined diseases included in the CCI, is expressed as weights with values of $1,2,3$, or 6 . Summing the weights for all contributing diseases gives the CCI score for each patient. The CCI is calculated 
based on codes in the International Classification of Diseases (ICD-10). Information about the patients' comorbid conditions as ICD-10 codes was collected from the National Patient Registry (NPR), which includes data on all patients treated in Norwegian government-funded hospitals.

\section{Questionnaire}

Patient Experience was measured using the Picker Patient Experience Questionnaire (PPE-15) [27]. The final choice of questionnaire was a result of several discussions between the researchers and collaborating physicians in the community over a one-year period. Even though other translated and validated instruments existed, they were viewed either as too extensive or too short (not covering all areas of interest). The PPE-15 was developed to elicit feedback from patients to highlight aspects of care that needed improvement and to monitor performance and care. It consists of 15 questions distributed to seven dimensions of care: respect, coordination, information/communication/education, physical comfort, emotional support, involvement of relatives, and transitions and continuity [27, 28] (Appendix). The questions have two ("yes" or "no") to four response options ("yes"," no", "I did not need to", or "yes, to some extent"). Neutral answers, such as "I did not need to", and the most positive answer are coded as a "non-problem" (score $=0$ ). The remaining responses are coded as "problems" (score $=1$ ). The PPE-15 has previously been found to be valid and reliable [28].

The PPE-15 has not been translated into Norwegian, and forwards and backwards translation were consequently performed according to recommendations in the literature [29, 30]: Two professional bilingual translators with Norwegian as their mother tongue performed two independent translations into Norwegian. After comparing the translations and synthesizing these into one, the questionnaire subsequently underwent a backward translation to English by a translator with English as her mother tongue. Finally, three independent individuals evaluated the questionnaire by comparing the English and Norwegian versions with regard to semantic, idiomatic, experiential, and conceptual equivalence. Following this procedure and prior to statistical testing, the Norwegian PPE-15 underwent testing of face validity. This was done by distributing the questionnaire to 10 patients prior to the study period in order to assess the adequacy, appropriateness and understandability of the questionnaire, including language and scoring instructions [31]. Patient feedback did not reveal any problematic issues in any of these aspects. Following these procedures, a final version of the PPE-15 was approved and tested.

To assess patients' self-reported health, we used the EuroQOL 5-dimension, 3-level version (EQ-5D-3 L) [32, 33]. The EQ-5D-3 L consists of the EQ-5D descriptive system that measures health-related quality of life on five dimensions: mobility, self-care, usual activities, pain/discomfort, anxiety/ depression, and the EQ visual analogue scale (EQ VAS). Responses are scored according to three levels: 0 (no problem), 1 (some problems) to 2 (severe problems). The EQ5D-3 L score was used as an overall EQ-5D-3 L index score by assigning weights to each level of each dimension according to the Europe VAS value set [32, 34].

\section{Procedure}

The following standardised inclusion procedure was used: 1) Prior to discharge, the study nurses provided the patients with oral information about the purpose of the study. 2) At discharge, the patients received written information, the study questionnaires and a consent form. 3) The patients were asked to complete these forms at home and were instructed to return the completed questionnaires, along with the signed informed consent form, in a pre-stamped envelope. Nonresponders were reminded once by a phone call from the first author approximately 2 weeks after discharge.

\section{Statistical analysis}

Summative statistics were used to present characteristics of the sample. Because the data (age, length of stay, comorbidity and self-rated health) were not normally distributed, the continuous variables are displayed as the median, mean and standard deviation. Because no method for calculating missing items exists for the PPE-15, and based on recommendations from statistical expertise at the Picker Institute (personal communication - available from the first author upon request), missing items were not included in the analysis. A Mann-Whitney $U$ test was used to evaluate differences between responders and non-responders.

To assess convergent validity, Spearman's correlation between of the PPE-15 items and items in the previously validated Nordic Patient Experience Questionnaire (NORPEQ) questionnaire was used. The NORPEQ consists of six questions that cover important aspects of healthcare encounters and is scored from the worst experience (0) to the best experience (100) [35]. We hypothesised that a generally moderate correlation would be found between the two questionnaires because the PPE-15 and NORPEQ do not capture exactly comparable aspects of the patient experience. We also hypothesised that the second item of the NORPEQ would have an overall low correlation with the PPE-15, since none of the items in the PPE-15 measure doctors' professional skills.

Internal consistency of the PPE-15 was assessed by Cronbach's alpha. In order to measure test-retest reliability of the PPE-15, a subgroup of responders was invited to fill out the PPE-15 a second time, approximately 3 weeks after the first completion. Invitation to participate in retest was sent consecutively as completed questionnaires were 
received. The literature suggests that only patients in a stable condition should be included in the re-test, since responses may be influenced by a change in health status [36]. Hence, patients were also asked to indicate whether their condition was unchanged, had deteriorated or improved. Test- retest was assessed using the Cohens' unweighted Kappa statistics. Kappa less than 0.2 is defined as 'poor agreement', $0.2-0.4$ as 'fair agreement', 0.4 to 0.6 as 'moderate agreement', 0.6 to 0.8 as 'good agreement', and a kappa $=0.8$ to 1.0 as 'very good agreement' [37].

The proportion of the PPE-15 items scored as a 'problem' (dependent variable, in long format) was estimated by a binomial linear mixed model [38-40] that used socio-demographic variables, length of stay, the Charlson score and the EQ-5D index score as covariates (independent variables). Some of the variation in the patients' scores can be attributed to individual experiences as well as to aspects of the different locations (e.g., the staffing situation and the type of services they offer) [39]. The care wards and patients (identity) were consequently included as random effects to account for the inhomogeneity among patients and inhomogeneity among wards. Insignificant variables were removed from the model one at a time until only significant effects remained. The ICC was calculated to explore the proportion of random variation.

All tests were two-sided, used a 95\% confidence interval (CI) and used a significance level of 0.05. All analyses were performed using Statistical Package for the Social Sciences (SPSS) version 21 [41].

\section{Results}

During the inclusion period, 1235 (56.6\%) patients, out of the 2182 patients who were admitted to the five MAWs, received a questionnaire. The proportion of discharged patients who received a questionnaire varied from $36.9 \%$ to $68.9 \%$ in the five MAWS. A total of 479 patients (38.8\%) returned the questionnaires. Table 1 presents an overview of the responders' socio-demographic characteristics, length of stay, Charlson comorbidity score and self-rated health.

For non-responders, mean age was 78.1 years (median $=83$, SD 15.2), 36.2\% male. Compared with responders, nonresponders were older $(p<0.001)$ and fewer were male $(p<0.001)$.

\section{PPE-15, validity and reliability}

The correlation between the NORPEQ and the PPE-15 items varied between -0.46 and 0.43 (Table 2). The internal consistency of the PPE-15 as assessed by Cronbach's alpha was 0.83 .

Cohens' unweighted Kappa statistics varied from 0.27 (fair agreement) - 0.7 (good agreement), except from on PPE-15 item 11, in which the agreement was 0.13 (poor) (Table 3).
Table 1 Study responders' socio-demographic characteristics, length of stay, Charleson co-morbidity score and self-rated health

\begin{tabular}{ll}
\hline Male & $41.8 \%$ \\
\hline Mean age (SD)- in years & $74.9(14.5)$ \\
Median age- in years & 78.0 \\
Relationship (yes) & $51.7 \%$ \\
Living alone (yes) & $49 \%$ \\
Higher education (yes) & $18.5 \%$ \\
Work (yes) & $9 \%$ \\
Mean length of stay (SD)-in days & $3.73(2.3)$ \\
Mean CCIS (SD) & $1.09(1.6)$ \\
Mean EQ5D3L (SD) & $.52(.26)$ \\
\hline
\end{tabular}

Abbreviations and table legends: MAWs municipality acute wards, Male the percentage of males in the sample, SD standard deviation, Relationship-married or in a relationship (Not in relationship- single or widower/widow). Higher educationhigh school level or above. Work- responders still working. CCIS- Charleson comorbidity index score ${ }^{\mathrm{a}}$. EQ5D-EuroQol 5-dimension-3 level version index score ${ }^{b}$

${ }^{\mathrm{a}} \mathrm{CCIS}$ is based on nineteen predefined diseases, expressed with the values $1,2,3$ or 6 , are included in the $\mathrm{CCl}$ based on their association with one-year mortality. Summing the weights gives the $\mathrm{CCI}$ score (CCIS) for each patient ${ }^{b}$ Calculated with the Europe VAS score. Score range $0-1$, where 0 indicates perfect health (no problems), and 1 indicates worst possible health (extreme problems on all items)

\section{Patient experiences and association with background characteristics}

The number of respondents who reported each PPE-15 item as a problem and the item's corresponding dimension are presented in Table 4. Fourteen of the respondents did not report any problems.

The largest proportion of problems was observed in the continuity and transition dimension of the PPE-15, particularly the item related to information about dangerous signals to watch for at home (73.3\%). The smallest proportion of problems were observed for the item related to being treated with respect and dignity, and the item asking whether doctors talked in front of them as if they were not there (8.8\%, respectively). Furthermore, $42.1 \%$ of patients reported problems related to their involvement in treatment and care. While 25.5\% of patients reported problems related to whether explanations about the purpose of medicines were understandable, and $51.2 \%$ reported problems related to information about medication side effects.

The random effects analysis revealed a negligible variation among wards (ICC $<0.001)$, whereas the random variation between patients within wards contributed to $21 \%$ of the total random variation. In the binominal linear mixed model only the Charlson comorbidity score was statistically significantly associated with decreased patient experience, while factors such as gender, age, self-rated health, length of stay, educational background, employment status, housing status and civil status were not associated with patient experiences (Table 5). 
Table 2 Correlations (Spearman Rho) between the items in the NORPEQ and the PPE-15 $(n=68)^{\mathrm{a}}$

\begin{tabular}{lllllll}
\hline PPE-15 ITEMS & $\begin{array}{l}\text { NORPEQ 1 "Understanding } \\
\text { doctors" }\end{array}$ & $\begin{array}{l}\text { NORPEQ 2 "Trust } \\
\text { doctors" }\end{array}$ & $\begin{array}{l}\text { NORPEQ 3 "Trust } \\
\text { personnel" }\end{array}$ & $\begin{array}{l}\text { NORPEQ 4 "Caring } \\
\text { personnel" }\end{array}$ & $\begin{array}{l}\text { NORPEQ 5 "Interested } \\
\text { personnel" }\end{array}$ & $\begin{array}{l}\text { NORPEQ 6 "Receive } \\
\text { information" }\end{array}$ \\
\hline PPE-1 & $-0.45^{* *}$ & $-0.27^{*}$ & $-0.29^{*}$ & -0.20 & $-0.39^{* *}$ & $-0.34^{* *}$ \\
PPE-2 & $-0.32^{* *}$ & -0.18 & $-0.26^{*}$ & $-0.23^{*}$ & $-0.34^{* *}$ & $-0.36^{* *}$ \\
PPE-3 & $0.23^{*}$ & $0.24^{*}$ & $0.23^{*}$ & $0.26^{*}$ & $0.28^{*}$ & 0.21 \\
PPE-4 & -0.19 & -0.01 & -0.14 & $-0.39^{* *}$ & $-0.23^{*}$ & -0.23 \\
PPE-5 & $0.27^{*}$ & 0.22 & 0.09 & 0.17 & $0.30^{* *}$ & $0.31^{* *}$ \\
PPE-6 & $0.39^{* *}$ & $0.33^{* *}$ & 0.18 & $-0.27^{*}$ & $0.28^{*}$ \\
PPE-7 & -0.22 & -0.08 & $-0.28^{*}$ & $-0.28^{*}$ & -0.20 & -0.22 \\
PPE-8 & -0.09 & -0.00 & -0.11 & $-0.31^{* *}$ & -0.17 & -0.19 \\
PPE-9 & -0.15 & -0.07 & -0.19 & $-0.46^{* *}$ & $-0.36^{* *}$ & $-0.27^{*}$ \\
PPE-10 & -0.13 & -0.17 & $-0.29^{*}$ & $-0.26^{*}$ & $-0.34^{* *}$ & $-0.26^{*}$ \\
PPE-11 & -0.03 & -0.20 & -0.18 & $-0.29^{*}$ & -0.17 & -0.10 \\
PPE-12 & 0.07 & -0.19 & -0.22 & $-0.33^{* *}$ & -0.07 & -0.16 \\
PPE-13 & -0.03 & -0.13 & $-0.31^{* *}$ & $-0.25^{*}$ & -0.11 & -0.09 \\
PPE-14 & -0.05 & 0.04 & -0.22 & -0.20 & -0.08 & -0.12 \\
PPE-15 & -0.17 & -0.05 & $-0.31^{* *}$ & -0.22 & $-0.31^{* *}$ & $-0.33^{* *}$
\end{tabular}

NORPEQ items: 1 = did doctors talk so that you could understand them? 2 = did you trust the doctors' professional skills? $3=$ did you trust the personells' professional skills? $4=$ did you experience that the personell cared for you? $5=$ were the doctors and personell interested in your situation? $6=$ did you receive information about tests and examinations? PPE-15 items as described in Appendix. Correlations as measured by the Spearman's rho. ${ }^{* *}$-significant at a 0.01 level (2-tailed). *-significant at a 0.05 level (2-tailed). The highest correlations are in bold face

${ }^{a} \mathrm{~A}$ positive correlation coefficient indicates a positive relationship between the two variables (the larger value PPE, the larger value NORPEQ) while a negative correlation coefficients expresses a negative relationship (the larger value PPE, the smaller value NORPEQ)

Table 3 Test-retest of the PPE-15 using unweighted Kappa coefficient $(n=68)$

\begin{tabular}{lll}
\hline PPE-15 item & Kappa & $p$-value \\
\hline PPE-1 & 0.431 & $<.001$ \\
PPE-2 & 0.538 & $<.001$ \\
PPE-3 & 0.431 & $<.001$ \\
PPE-4 & 0.447 & $<.001$ \\
PPE-5 & 0.409 & $<.001$ \\
PPE-6 & 0.562 & $<.001$ \\
PPE-7 & 0.698 & $<.001$ \\
PPE-8 & 0.297 & .012 \\
PPE-9 & 0.400 & .001 \\
PPE-10 & 0.597 & $<.001$ \\
PPE-10a & 0.473 & $<.001$ \\
PPE-11 & 0.125 & .275 \\
PPE-12 & 0.311 & .008 \\
PPE-13 & 0.266 & .018 \\
PPE-14 & 0.479 & $<.001$ \\
PPE-15 & 0.357 & .002 \\
\hline Abbrvition & PPEPiker Patent Exper
\end{tabular}

Abbreviations: PPE Picker Patient Experience Questionnaire-15 items as described in the Appendix

\section{Discussion}

Findings indicate that the Norwegian PPE-15 is a valid and reliable patient experience questionnaire. Furthermore, among patients admitted to MAWs, the highest proportion of problems were related to aspects of 'continuity and transition'. Increased comorbidity was the only factor that was significantly negatively associated with patients' experiences in this study.

\section{PPE-15, validity and reliability}

The PPE-15 has primarily been tested in hospitalised patients [28]. The dimensional structure is based on input from patients during it's development and not on any statistical tests, such as e.g., factor analysis [27]. The latter might be because no dimensional score exist. Consequently, the dimensions reported only reflect what items are perceived by patients to be semantically related. Similar testing have been performed in Sweden [42]. As a consequence of the procedures used in prior studies and scoring instructions, a factor analysis was not used in the current study. However, during the assessment of face validity, patients did not report any specific issues related to neither the content of PPE-15 nor the items corresponding dimensions.

Testing of convergent validity revealed an overall weak to moderate correlation between the NORPEQ and the PPE15 items. This may be because the specific content of each item differs between these two questionnaires. However, 
Table 4 Proportion of responders reporting problems on the items of Picker Patient Experience Questionnaire (PPE-15)

PPE-15 item
from doctors [70]
2) Understandable answers to questions
from nurses [70]
3) Different answers from different
personnel [70]
4) Discuss anxieties/fears about condition/
treatment with doctor (3)
5) Doctors talk in front of you, as if you
weren't there? (4)
6) Involvement in care and treatment
decisions? (4)
7) Treated with respect and dignity (4)
8) Discuss anxieties/ fears about condition/
treatment with nurse (3)
9) Someone in staff to talk to about
concerns? (3)
10) Were you ever in pain? (yes)
10a) Staff took action to relieve pain (5)
11) Opportunity for family/close persons
to talk to doctor (6)
12) Enough information to family or
someone close to help recover? (6)
13) Understandable explanation about
15) Informatects ( 7 )
observe at home of medicines ( 7 )
14)

Abbreviations and table legends: MAWs municipal acute wards,

PPE-15-Picker Patient

Experience Questionnaire. PPE-15 item-the 15 items, with dimension 1-7 in parenthesis; $1=$ Information and education, $2=$ Coordination of care, $3=$ Emotional comfort, $4=$ Respect patient preferences, $5=$ Physical comfort, $6=$ Involvement of family and friends, $7=$ Continuity and transition. PPE-15 item- Picker Patient Experience Questionnaire, short version of the 15 questions. The proportion of responders reporting a problem on number of answers to each of the PPE-15 items. Percentage in parenthesis

correlations were generally higher in those items hypothesised to be more closely associated, and lower in those not hypothesised as associated. This may indicate that the PPE15 has an acceptable convergent and discriminant validity.

The Kappa values varied from fair to good agreement in the vast majority of items. In item 11, concerning whether family and close ones had the possibility to talk to a doctor if they were in need or wanted to, the agreement was poor. The potential reason for this finding is unclear and future studies using the PPE-15 should explore this more closely.

\section{Patient experiences}

Our results show that the vast majority of patients reported that they were treated with respect and dignity,
Table 5 Results from the binomial linear mixed model of the PPE-15, using care wards $(n=5)$ and patients $(n=479)$ as random effects

\begin{tabular}{llll}
\hline & OR & $\mathrm{Cl}(95 \%)$ & $p$-value \\
\hline Civil status & 1.001 & $(0.581-1.726)$ & .997 \\
Educational background & 0.988 & $(0.788-1.255)$ & .922 \\
Housing status & 1.020 & $(0.841-1.237)$ & .839 \\
EQ5D3L & 1.050 & $(0.789-1.397)$ & .738 \\
Employment status & 0.670 & $(0.066-6.774)$ & .734 \\
Gender & 0.982 & $(0.773-1.113)$ & .420 \\
Age & 1.004 & $(0.997-1.010)$ & .259 \\
Length of stay & 1.045 & $(1.009-1.081)$ & .13 \\
CCIS & 1.085 & $(1.011-1.164)$ & .023 \\
\hline
\end{tabular}

Abbreviations and table legends: $O R$ odds ratio, $\mathrm{Cl}$ confidence interval, EQ5D3L EuroQol 5-dimension-3 level version index score, CCIS Charleson comorbidity index score. Insignificant variables were removed from the model one at a time until only significant effects remained. The $\mathrm{OR}, \mathrm{Cl}$ and $P$-values presented in this table is the value of each factor prior to being omitted in the step-wise analysis (please see methods)

which corresponds with findings from a qualitative study [25]. Nevertheless, many wanted greater involvement in decisions about their care and treatment. Although this finding is in line with a study of 34,000 hospitalised patients in Sweden [43], our results seem to contrast prior reports that have observed a positive association between respect/dignity and involvement in care [44]. Patientcentred care has been described as a partnership between patients and healthcare professionals to inform and involve patients in shared decision making [45]. Outcomes have been suggested to include patients' feeling of respect, involvement, engagement and knowledge [46].

Patients in the current study also experienced problems related to continuity and transition. Prior studies have shown that poor communication, incomplete transfer of information, and inadequate education of the patients may have a negative impact on care transitions, leading to unplanned readmissions and adverse events [47, 48]. In particular, problems were reported concerning information about potential medication side effects to observe at home. Drug-related problems (DLPs) occur quite frequently after discharge, and factors such as a short stay and inadequate communication may influence the figure negatively [49]. Studies have however found that providing elderly patients with medication reports may reduce this amount [49, 50]. Interestingly, 24$24.8 \%$ of patients in our study reported problems related to receiving understandable answers to questions from either nurses or doctors, while $31.2 \%$ reported that they had received different answers to questions from different personnel. Studies have found that significant differences exist between what physicians think patients know and what patients actually know [51]. Because we do not have any specific information on how the discharge 
process was handled at each treatment location, it is beyond the scope of this paper to draw any firm conclusions in that regard. Nevertheless, the variation among care wards was negligible in the current study. However, given the importance of discharges and handovers, it seems important to target quality of patient and healthcare personnel communication to improve how patients experience their healthcare encounter [52].

The results from our study show that the random effect attributed to the ward to which patients were admitted had very little influence on patient experiences. This may be due to a relatively small sample size, or that participants were included from one county were the MAW routines were quite homogenous, due to joint collaborative efforts. Interestingly, prior studies have argued that for most quality aspects, including the ward into analyses of patient experiences is important for a number of quality indicators [53].

\section{Factors influencing patient experiences}

Our findings show that age, gender, civil status, employment status, educational status, housing status, self-rated health and length of stay had no significant effect on the number of problems. This is in contrast to earlier research reporting that increased age and decreased self-reported health status are the strongest predictors of negative patient experiences [54]. Additionally, one study found that at least $79 \%$ of the variance of all patient experience measures occurred at the patient level [9]. In a study of 34,000 Swedish hospitalised patients, poorer experiences were associated with greater healthcare utilisation, higher age, functional impairment and female gender. Previous studies have also suggested a positive association between older age and higher care satisfaction [54, 55]. However, studies on primary care services have also been inconsistent regarding the relative influence of health and socioeconomic status, age, gender, ethnicity and self-rated health on patient reported experiences [56, 57]. It might be speculated if our findings occurred because the PPE-15 uses a dichotomised score.

A greater number of comorbid conditions was weakly, but significantly negatively associated with patient experiences. Comorbidity is associated with worse health outcomes, more complex clinical management, and increased health care costs [58]. In older adults, comorbidity is one of three factors (along with frailty and disability) that are commonly used to indicate vulnerability [59]. Vulnerable patients have also reported fewer positive care experiences than non-vulnerable patients in prior studies [43]. Healthcare professionals may view vulnerable patients as individuals who have more complex healthcare needs; thus, they may focus on meeting these needs rather than focusing on patient satisfaction or patient experiences [43].

\section{Limitations}

Increasing time since discharge seems to result in poorer patient experiences scores, and patients who self-report their experiences at home following discharge may consequently have an increased risk of recall bias [60]. While collecting data before discharge from MAWs could have increased the number of respondents and reduced the risk of recall bias, the responses could also have been influenced by potential interruptions and influence of the personnel [61].

Sadly, not all patients who were discharged from the five MAWs were invited to participate, as planned. This could indicate a potential selection bias. Based on input from the various MAWs and study follow-up, there did not seem to be any pattern regarding who was invited and who was not. The reasons seemed to be lack of time due to many tasks, and forgetfulness. Another drawback is that we did not collect information on those who did not receive a questionnaire, which of course makes it impossible to assess any differences between those who were invited and those who were not. Moreover, the response rate is relatively low. It is therefore difficult to know if those not responding had worse experiences, which has been reported in the literature [62]. Comparison of non-responders and responders furthermore revealed significant differences in gender and age.

In retrospect, we could have invited a larger number of patients in the retest, yet the number of patients needed in these tests have been subject of debate. For instance some have advocated that a sample size of 50 could be sufficient or a starting point, while others have highlighted the need for larger sample sizes and more robust test-retest data [63, 64]. Indeed, a systematic review found that the median number included in retest analysis was 60 [36].

Patients may judge an organisation in light of personal expectations, and this may not adequately reflect actual care quality. Pre-existing higher expectations of care quality have been linked to increased critical evaluation of a healthcare service [65]. Our study did not include questions about patient expectations, and consequently, we cannot conclude whether worse experiences reflect suboptimal care or different expectations [66]. However, because MAWs are newly established health services, patients may not adequately know what to expect when they are treated in these units [24].

\section{Conclusion}

The PPE-15 displayed acceptable validity and reliability. While patients reported problems in all of the PPE-15 items, this was particularly evident in aspects related to discharge information. These findings may be helpful in planning ways to improve quality of care, e.g., by providing feedback to healthcare personnel, or by using patient experience as a quality indicator. Findings may also be important when developing new decentralised acute health care services. 


\section{Appendix}

Table 6 Domains, items and scoring alternatives of the Picker Patient Experience Questionnaire

\begin{tabular}{ll}
\hline Domain and Item & Scoring alternatives \\
\hline Information and education & \\
Item 1 - When you had important questions to ask a doctor, did you get & Yes, always/Yes, sometimes/No/l had no need to ask \\
answers that you could understand? & \\
Item 2 - When you had important questions to ask a nurse, did you get & Yes, always/Yes, sometimes/No/l had no need to ask
\end{tabular}

answers that you could understand?

\section{Coordination of care}

Item 3 - Sometimes in a hospital, one doctor or nurse will say one thing and another will say something quite different. Did this happen to you?

Emotional comfort

Item 4 - If you had any anxieties or fears about your condition or treatment, did a doctor discuss them with you?

Item 8 - If you had any anxieties or fears about your condition or treatment, did a nurse discuss them with you?

Item 9 - Did you find someone on the hospital staff to talk to about your concerns?

Respect patient preferences

Item 5 - Did doctors talk in front of you as if you weren't there?

Yes, often/Yes sometimes/No

Item 6 - Did you want to be more involved in decisions made about your care and treatment?

Item 7 - Overall, did you feel you were treated with respect and dignity while you were in hospital?

Physical comfort

Item 10 - Were you ever in pain?

Yes/No

Item 10 a - If yes...

Do you think the hospital staff did everything they could to help control your pain?

Involvement of family and friends

Item 11 - If your family or someone else close to you wanted to talk to a doctor, did they have enough opportunity to do so?

Item 12 - Did the doctors or nurses give your family or someone close to you all the information they needed to help you recover?

Yes, completely/Yes, to some extent/No/I didn't have any anxieties or fears

Yes, completely/Yes, to some extent/No/I didn't have any anxieties or fears

Yes, definitely/Yes, to some extent/No/l had no concerns

Yes, definitely/Yes, to some extent/No

Yes, always/Yes, sometimes/No

Yes, definitely/Yes, to some extent/No

Yes, definitely/Yes, to some extent/No/No family or friends were involved/My family didn't want or need information/l didn't want my family or friends to talk to a doctor

Yes, definitely/Yes, to some extent/No/No family or friends were involved/My family or friends didn't want or need information

Continuity and transition

Item 13 - Did a member of staff explain the purpose of the medicines you were to take at home in a way you could understand?

Yes, completely/Yes, to some extent/No/I didn't need an explanation/l had no medicines - go to question 15

Item 14 - Did a member of staff tell you about medication side effects to watch for when you went home?

Item 15 - Did someone tell you about danger signals regarding your illness or treatment to watch for after you went home?

Yes, completely/Yes, to some extent/No/l didn't need an explanation

Yes, completely/Yes, to some extent/No

\section{Abbreviations}

CCIS: Charleson comorbidity index score; EQ5D: EuroQol 5-dimension-3 level version index score; MAW: Municipality acute ward; PPE-15: Picker Patient Experience Questionnaire

\section{Acknowledgements}

The authors would like to thank all the study participants as well as study nurses and physicians at the five MAWs. MD Per Grunde Weydahl and MD Paul Barack are acknowledged for contributing to the planning of this project.

\section{Funding}

The study was funded by an unrestricted research grant from the Østfold Hospital Trust

\section{Availability of data and materials}

The datasets generated and/or analysed during the current study are not publicly available due to local ownership of the data, but are available from the corresponding author on reasonable request. 


\section{Authors' contributions}

ACLL performed the data collection and scanning of the data. Together with LPJJ and RH did the analysis and interpretation of data. ACLL wrote a first edition of the full manuscript, of which all of the co-authors participated in the drafting and critical revision of the manuscript for important intellectual content, as well as approval of the final submitted version of the manuscript. All co-authors contributed in the conception and planning of the work that led to the manuscript, analysis and interpretation of the data. All authors read and approved the final manuscript.

\section{Ethics approval and consent to participate}

The study was performed according to the principles stated in the Declaration of Helsinki. The study was approved by the Regional Committees for Medical and Health Research Ethics (REC) in Norway (ref. no 2013/1276/REK sør-øst D) and the Norwegian Social Science Data Services (NSD) (ref. no 38585). Written informed consent was obtained from all of the study participants.

\section{Consent for publication}

Not applicable.

\section{Competing interests}

All authors declare that they have no competing interests.

\section{Publisher's Note}

Springer Nature remains neutral with regard to jurisdictional claims in published maps and institutional affiliations.

\section{Author details}

'Østfold Hospital Trust, University of Oslo, P.O. Box 300, NO-1714 Grålum, Norway. ${ }^{2}$ Østfold University College, Østfold Hospital Trust, P.O. Box 700, NO-1757 Halden, Norway. ${ }^{3}$ Indre Østfold Kompetansesenter, Askim Municipality, Eventyrveien 2, NO-1807 Askim, Norway.

${ }^{4}$ Intermediæravdelingen, Halden Municipality, Kjærlighetsstien 28, NO- 1781 Halden, Norway. ${ }^{5}$ Peer Gynt Helsehus, Moss Municipality, Peer Gynts vei 86, NO- 1535 Moss, Norway. ${ }^{6}$ Sarpsborg Municipality, P.O. Box 237, NO- 1702 Sarpsborg, Norway. ${ }^{7}$ Fredrikstad Municipality, P.O. Box 1405, NO-1602 Fredrikstad, Norway. ${ }^{8}$ Syddansk Universitet, Campusvej 55, DK-5230 Odense M, Denmark.

Received: 1 November 2016 Accepted: 12 September 2017

\section{Published online: 29 September 2017}

\section{References}

1. NHS Institute for Innovation and Improvement. The patient experience book. A collection of the NHS Institute for Innovation and Improvement guidance and support. Coventry: University of Warwick Science Park; 2013.

2. Doyle $C$, Lennox L, Bell D. A systematic review of evidence on the links between patient experience and clinical safety and effectiveness. BMJ Open. 2013;3(1):e001570

3. Rathert C, Brandt J, Williams ES. Putting the 'patient' in patient safety: a qualitative study of consumer experiences. Health Expect. 2012;15(3):327-36.

4. Bjertnaes $\mathrm{O}$, Sjetne I, Iversen $\mathrm{H}$. Overall patient satisfaction with hospitals: effects of patient-reported experiences and fulfilment of expectations. BM Qual Saf. 2012;21(1):39-46.

5. Garratt A. National and cross-national surveys of patient experiences. Oslo: Nasjonalt kunnskapssenter for helsetjenesten [Norwegian Knowledge Centre for the Health Services]; 2008.

6. LaVela S, Gallan A. Evaluation and measurement of patient experience. Pat Exp J. 2014:1(1):28-36.

7. Luxford K. What does the patient know about quality? Int J Qual Health Care. 2012;24:439-40.

8. Ahmed F, Burt J, Roland M. Measuring patient experience: concepts and methods. Patient. 2014;7(3):235-41.

9. Salisbury C, Wallace M, Montgomery A. Patients'experience and satisfaction in primary care: a secondary analysis using multilevel modelling. BMJ. 2010; 341:5004.

10. Grøndahl V, Wilde-Larsson B, Hall-Lord M, Karlsson I. A pattern approach to analysing patients' satisfaction and quality of care perceptions in hospital. Int J Pers Cent Med. 2011;1(4):766-75.
11. Johnson M, Rodriguez $\mathrm{H}$, Solorio M. Case-mix adjustment and the comparison of community health center performance on patient experience measures. Health Serv Res. 2010;45:670-90.

12. Paddison C, Saunders C, Abel G, Payne R, Campbell J, Roland M. Why do patients with multimorbidity in England report worse experiences in primary care? Evidence from the general practice patient survey. BMJ Open. 2015;5(3):e006172.

13. Grøndahl VA, Karlsson I, Hall-Lord ML, Appelgren J, Wilde-Larsson B. Quality of care from patients' perspective: impact of the combination of personrelated and external objective care conditions. J Clin Nurs. 2011;20(17-18): 2540-51.

14. Skudal K, Garratt A, Eriksson B, Leinonen T, Simonsen J, Bjertnaes O. The Nordic patient experiences questionnaire (NORPEQ): cross-national comparison of data quality, internal consistency and validity in four Nordic countries. BMJ Open. 2012;2(3):e000864. doi:10.1136/bmjopen-2012-000864.

15. Wiig S, Storm M, Aase K, Gjestsen MT, Solheim M, Harthug S, et al. Investigating the use of patient involvement and patient experience in quality improvement in Norway: rethoric or reality? BMC Health Serv Res. 2013;13:206

16. Norwegian department of health and care. Nasjonal helse- og omsorgsplan [national health and care plan] Oslo: 2010-11. Report No. 16.

17. Norwegian department of health and care. Samhandlingsreformen. Rett behandling-til rett tid-på rett sted [ The coordination reform. Proper treatment in right time and place]. Report No. 47. Available from: https:// www.regjeringen.no/contentassets/d4f0e16ad32e4bbd8d8ab5c21445a5dc/ en-gb/pdfs/stm200820090047000en_pdfs.pdf. Accessed 3 Feb 2016.

18. Norsk forening for allmennmedisin [Norwegian Association for General Practice]. Medisinskfaglig veileder for kommunale akutte døgnplasser [ medical guidelines for municipal acute wards]. Oslo: Den norske legeforening [the Norwegian Medical Association]; 2014

19. Skinner M. Øyeblikkelig hjelp døgnopphold. Oppsummering av kunnskap og erfaringer fra de første fire årene med kommunalt øyeblikkelig hjelp døgnopphold [acute care wards. Summarisation of knowledge and experiences from the four first years of municipal acute care units]. Gjøvik: Høgskolen i Gjøvik; 2015.

20. Young J. The development of intermediate care services in England. Arch Gerontol Geriatr. 2009;49(Suppl 2):S21-5.

21. Primary Care Foundation. Urgent care centres: what works best? A discussion paper. 2012

22. Li P, Schneider JE, Ward MM. Effect of critical access hospital conversion on patient safety. Health Serv Res. 2015; 42(6):2089-108.

23. Martinsen B, Norlyk A, Lomborg K. Experiences of intermediate care among older people: a phenomenological study. Br J Comm Nurs. 2015;20(2):74-9.

24. Leonardsen A, del Busso L, Grøndahl V, Ghanima W, Barach P, JelsnessJørgensen L. A qualitative study of patient experiences with decentralised acute healthcare services. Scand J Prim Health Care 2016; 34(3): 317-324.

25. Leonardsen A, Del Busso L, Grøndahl V, Jelsness-Jørgensen L. "It's a whole human being": a qualitative study of care experiences among patients treated in decentralised healthcare services. EJPCH. 2017;5(1):82-7.

26. Charlson ME, Pompei P, Ales KL, MacKenzie CR. A new method of classifying prognostic comorbidity in longitudinal studies: development and validation. J Chron Dis. 1987:40(5):373-83.

27. Jenkinson C, Coulter A, Bruster S. The picker patient experience questionnaire: development and validation using data from in-patient surveys in five countries. Int J Qual Health Care. 2002;14(5):353-8.

28. Jenkinson C, Coulter A, Reeves R, Bruster S, Richards N. Properties of the picker patient experience questionnaire in a randomized controlled trial of long versus short form survey instruments. J Pub Health Med. 2003;25(3):197-201.

29. Wild D, Grove A, Martin M, Eremenco S, McElroy S, Verjee-Lorenz A, et al. Principles of good practice for the translation and cultural adaptation process for patient-reported outcomes (PRO) measures: report of the ISPOR task force for translation and cultural adaptation. Value Health. 2005; 8(294-104).

30. Mokkink L, Terwee C, Patrick D, Alonso J, Stratford P, Knol D, et al. The COSMIN checklist for assessing the methodological quality of studies in measurement properties of health status measurement instruments: an international Delphi study. Qual Life Res. 2010;19(4):539-49.

31. Polit D, Beck C. Nursing research principles and methods. 9th ed. Baltimore: Lippincott Williams \& Wilkins; 2012

32. EuroQol Group. EuroQol- a new facility for the measurement of healthrelated quality of life. Health Policy. 1990;16(3):199-208. 
33. Esser A, Gube M, Schettgen T, Kraus T, Lang J. QUALY as evaulation in a health surveillance program. Available from: https://www.ncbi.nlm.nih.gov/ pubmed/24054544. Accessed 5 Nov 2015

34. Rabin R, de Charro F. EQ-5D-SD: a measure of health status from the Euroqol group. Ann Med. 2001;33(5):337-43.

35. Oltedal S, Garratt A, Bjertnaes O, Bjornsdottir M, Freil M, Sachs M. The NORPEQ patient experiences questionnaire: data quality, internal consistency and validity following a Norwegian inpatient survey. Scand J Pub Health. 2007;35(5):540-7.

36. Paiva C, Barroso E, Carneseca E, de Padua SC, dos Santos F, Lopez R, et al. A critical analysis of test-retest reliability in instrument validation studies of cancer patients under palliative care: a systematic review. BMC Med Res Methodol. 2014;14(8). https://doi.org/10.1186/1471-2288-14-8.

37. McHugh M. Interrater reliability: the kappa statistic. Biochem Med. 2012;22(3):276-82

38. Nelder J, Wedderburn R. Generalized Linear Models. J Royal Stat Soc. 1972:135(3):370-84.

39. Roberts M, Campbell J, Abel G, Davey A, Elmore N, Maramba I, et al. Understanding high and low patient experience scores in primary care: analysis of patients' survey data for general practices and individual doctors. BMJ. 2014;349:96034

40. McCulloch C, Searle S. Generalized, linear and mixed models. New York: Wiley; 2001.

41. IBM Corporation. IBM SPSS statistics for windows, version 21.0. New York: Armonk; 2012

42. Höglund A. Vad tycker patienten om vården? Delrapport från en provstudie med picker-metoden [what do patients think about their care? Part report from a test study with the picker method]. Lund: Sociologiska instituten; 1998.

43. Wolf A, Olsson L, Taft C, Sweberg K, Ekman I. Impacts of patient characteristics on hospital care experience in 34,000 Swedish patients. BMC Nurs. 2012;11(8). https://doi.org/10.1186/1472-6955-11-8.

44. Parlour R, Slater P, Mccormack B, Gallen A, Kavanagh P. The relationship between positive patient experience in acute hospitals and person-centred care. Int J Res Nurs. 2014;5(1):25-34.

45. O'Leary K, Killarney A, Hansen L, Jones S, Malladi M, Marks K, et al. Effect of patient-centred bedside rounds on hospitalised patients' decision control, activation and satisfaction with care. BMJ Qual Saf. 2015;25(12):921-8.

46. Gerteis M, Edgman-Levitan S, Daley J, Delbanco T. Through the patient's eyes: understanding and promoting patient -centered care. San Fransisco: Jossey-Bass; 1993.

47. Naylor M. Nursing intervention research and quality of care: influencing the future of healthcare. Nurs Res. 2003;52(6):380-5.

48. Apel E, O alley T, Greenwald J. Hospital discharge and readmission. 2016. Available from: uptodate.com. Accessed 6 June 2016.

49. Garcia-Caballos M, Ramos-Diaz F, Jimenez-Moleon JJ, Bueno-Cavanillas A. Drug-related problems in older people after hospital discharge and interventions to reduce them. Age Ageing. 2010;39(4):430-8.

50. Midlov $\mathrm{P}$, Holmdahl L, Eriksson T, Bergkvist A, Ljungberg B, Widner $\mathrm{H}$, et al. Medication report reduces number of medication errors when elderly patients are discharged from hospital. PWS. 2008;30(1):92-8.

51. Olson DP, Windish DM. Communication discrepancies between physicians and hospitalized patients. Arch Intern Med. 2010;170(15):1302-7.

52. Siemsen I, Madsen M, Pedersen L, Michaelsen L, Pedersen A, Andersen $H$, et al. Factors that impact on the safety of patient handovers: an interview study. Scand J Publ Health. 2012;40:439-48.

53. Krol MW, DeBoer D, Sixma H, Van Der Hoek L, Rademakers JJ, Delnoij DM. Patient experiences of inhospital care: a department matter and a hospital matter. Int J Qual Health Care. 2015;27(1):17-25.

54. Crow R, Gage H, Hampson S, Hart J, Kimber A, Storey L, et al. The measurement of satisfaction with healthcare: implications for practice from a systematic review of the literature. Health Technol Assess. 2002;6:1-244.

55. Xiao H, Barber J. The effect of perceived health status on patient satisfaction. Value Health. 2008;11(4):719-25.

56. Glynn L, Byrne M, Newell J, Murphy A. The effect of health status on patient's satisfaction with out-of-hours care provided by a family doctor cooperative. Fam Pract. 2004;21(6):677-83.

57. Danielsen K, Bjertnaes OA, Garratt A, Forland O, Iversen HH, Hunskaar S. The association between demographic factors, user reported experiences and user satisfaction: results from three casualty clinics in Norway. BMC Fam Pract. 2010;11:73-2296-11-73.
58. Valderas J, Starfield B, Sibbald B, Salisbury C, Roland M. Defining comorbidity: implications for understanding health and health services. Ann Fam Med. 2009;7(4):357-63.

59. Fried L, Ferrucci L, Darer J, Williamson J, Anderson G. Untangling the concepts of disability, frailty and comorbidity: implications for improved targeting and care. J Gerontol A Biol Sci Med Sci. 2004;59(3):255-63.

60. Bjertnaes $\mathrm{O}$. The association between survey time and patient-reported experiences with hospitals: results of a national postal survey. BMC Med Res Methodol. 2012;12(13). https://doi.org/10.1186/1471-2288-12-13.

61. French K. Methodological considerations in hospital patient opinion surveys. Int J Nurs Stud. 2003:40(5):525-41.

62. Barron D, West E, Reeves $R$, Hawkes D. It takes patience and persistence to get negative feedback about patients' experiences: a secondary analysis of national inpatient survey. BMC Health Serv Res. 2014;14(153). doi:10.1186/ 1472-696-14-153.

63. Stucky B, Periera C, de Vet H, Terwee C, Mokkink L, Knol D. Measurement in medicine: a practical guide. Qual Life Res. 2012;21(2):371-3.

64. Polit D. Getting serious about test-retest reliability: a critique of retest research and some recommendations. Qual Life Res. 2014;23(6):1713-20.

65. Lyratzopoulos G, Elliott M, Barbiere J, Henderson M, Staetsky L, Paddison C, et al. Understanding ethnic and other socio-demographic differences in patient experience of primary care: evidence from the English general practice patient survey. BMJ Qual Saf. 2012;21:21-9.

66. Saunders C, Abel G, Lyratzopoulos G. What explains worse patient experience in London? Evidence from secondary analysis of the cancer patient experience survey. BMJ Open. 2016;4. doi:10.1136/bmjopen-293004039

\section{Submit your next manuscript to BioMed Central and we will help you at every step:}

- We accept pre-submission inquiries

- Our selector tool helps you to find the most relevant journal

- We provide round the clock customer support

- Convenient online submission

- Thorough peer review

- Inclusion in PubMed and all major indexing services

- Maximum visibility for your research

Submit your manuscript at www.biomedcentral.com/submit
) Biomed Central 